\title{
Multidimensional Symptom Burden among Patients with Hemodialysis in Indonesia
}

\author{
Hinin Wasilah ${ }^{\star 1} \odot$; Dhea Natashia ${ }^{2} \odot$; Chen-Hui Huang ${ }^{3}{ }^{\circ}$; Hsing-Mei \\ Chen $^{4} \odot$; Miaofen Yen ${ }^{4} \bullet$ \\ ${ }^{1}$ Fatmawati Nursing Academy, Jakarta, Indonesia \\ ${ }^{2}$ Department Medical Surgical Nursing, Faculty of Nursing, Muhammadiyah University \\ of Jakarta, Indonesia \\ ${ }^{3}$ Department of Nursing, College of Medicine, National Cheng Kung University, Taiwan \\ ${ }^{4}$ Sigma Theta Tau, Lambda Beta-At-Large Chapter, Professor, Department of Nursing, \\ College of Medicine, National Cheng Kung University, Taiwan
}

\section{G openaccess}

\section{Jurnal Keperawatan Padjadjaran (JKP)}

Volume 9(2), 159-166 (C) The Author(s) 2021 http://dx.doi.org/10.24198/jkp. v9i2.1660

\section{Article Info}

Received : May 18, 2021 Revised : August 23, 2021

Accepted : August 29, 2021

Published : August 31, 2021

Corresponding author

Hinin Wasilah

Fatmawati Nursing Academy,

Jakarta, Indonesia Postal address: 12420, Phone: 62 812109100, E-mail: hininwasilah@ gmail.com

\section{Citation}

Wasilah, H., Natashia, D., Huang, C. H., Chen, H. M., \& Yen, M. (2021). Multidimensional Symptom Burden among Patients with Hemodialysis in Indonesia. Jurnal Keperawatan Padjadjaran, 9(2), 159-165. https://doi.org/10.24198/ jkp.v9i2.1660

\section{Website}

http://jkp.fkep.unpad.ac.id/index php/jkp

This is an Open Access article distributed under the terms of the Creative Commons Attribution-NonCommercial 4.0 International License.

E-ISSN: $2442-7276$ P-ISSN: 2338-5324

\begin{abstract}
Background: Patients with hemodialysis commonly experience multiple symptoms. Most of the previous studies analyzed the symptoms as one dimension such as the severity dimension. Conducting the comprehensive symptom assessment among patients with hemodialysis is necessary to gain a better understanding of the symptom burden.

Purpose: The aim of this study was to identify symptom burden among patients with hemodialysis comprehensively.

Methodss: This study was a descriptive study. A convenience sample of 320 patients undergoing hemodialysis was recruited from the dialysis units at two referral hospitals in Indonesia (Fatmawati Hospital and Cipto Mangunkusumo National Hospital). Indonesian Version of Chronic Kidney Disease - Symptom Burden Index (CKD-SBI) was used. For the data analysis, descriptive analysis was used.

Results: Total 320 subjects were collected. This study found that lack of energy was the highest physical symptom burden under 4 dimensions: occurrence $269(84.0 \%)$, severity (mean $=4.28, S D=3.08)$, distress (mean $=4.42, \mathrm{SD}=3.09$ ), and frequency (mean $=4.41, \mathrm{SD}=3.27$ ). Furthermore, decreased interest in sex was the highest psychological symptom burden under for dimensions: occurrence $210(65.6 \%)$, severity (mean $=3.39$, SD $=3.38)$, distress $($ mean $=2.92, \mathrm{SD}=2.99)$, frequency $($ mean $=3.70, \mathrm{SD}=$ 3.65).

Conclusion: Lack of energy and decreased interest in sex were consistently the highest symptom burden among patients with hemodialysis. Creating appropriate interventions and managing the symptoms experienced by patients with hemodialysis comprehensively is very important to improve their quality of life
\end{abstract}

Keywords: chronic kidney disease; hemodialysis; symptom burden.

\section{Introduction}

Patients with chronic kidney disease (CKD), as well as patients on haemodialysis, commonly experience multiple symptoms such as fatigue, pain, sexual problems, itching, nausea, vomiting, sleep disorders, and poor appetite (Almutary, Bonner, \& Douglas, 2016; Murtagh, Sheerin, AddingtonHall, \& Higginson, 2011; Thong et al., 2008). Symptoms among patients with haemodialysis are caused by uraemia, which is characterized by the accumulation of toxins in the blood due to the decline of kidney function (Vadakedath \& Kandi, 2017). Among patients on haemodialysis, multiple symptoms exert a total symptom burden. The symptom burden commonly causes negative experience related to physical, psychological, and emotional (Gapstur, 2007). The number of symptoms among patients with 
chronic kidney disease approximately ranged from 6 until 20 (Almutary, Bonner, \& Douglas, 2013).

The majority of the previous studies assessed symptoms as one dimension such as the severity dimension (Lee \& Jeon, 2015; Shim \& Cho, 2018). Whereas symptoms are better understood if captured comprehensively (Almutary, Douglas, \& Bonner, 2016; Lenz, Pugh, Milligan, Gift, \& Suppe, 1997). The comprehensive symptom assessment consists of two symptom domains (physical and psychological), and consists of four symptom dimensions (occurrence, frequency, severity, and distress) (Almutary et al., 2016; Lenz et al., 1997). Therefore, a valid, comprehensive measurement involving multidimensional aspects of the symptom burden is necessary to gain a better understanding of symptom burden among people with CKD, especially patients undergoing hemodialysis. The presence of symptoms burden may affect the patient's quality of life (Thong et al., 2008). Comprehensive assessment is important for nurse as health care providers in terms of delivering appropriate interventions and for identifying priorities of nursing interventions which can improve better quality of life, especially when the disease has progressed to the advanced stage (Almutary et al., 2016). Almutary et al. (2016) reported physical symptom as the most demanding compared to psychological symptoms.

The number of patients who require haemodialysis in the world is $5.3-10.5$ million in 2018 (International Society of Nephrology, 2018). Indonesian Renal Registry presented the number of patients on haemodialysis in Indonesia which increased rapidly from 52.8 thousand in 2016 to 77.8 thousand in 2017 (Indonesian Renal Registry, 2018). Due to the increasing number of patients on haemodialysis, conducting a study among this population is essential. Understanding comprehensive symptom burden among patients on hemodialysis also facilitates effective care plans and nursing interventions which can improve better quality of life of patients on hemodialysis.

\section{Methods}

\section{Design and Sampling}

In this study, the researcher utilized a descriptive study. The subjects were patients on hemodialysis. The number of samples is calculated by using rule of thumb 10 observations per variable (Comrey \& Lee, 1992). There are 32 items in the questionnaire used by the authors, thus the total sample was 320 patients. The samples were obtained from the hemodialysis unit in Fatmawati Hospital and Cipto Mangunkusumo Hospital by using convenience sampling technique. The inclusion criteria for this study were patients above 18 years old who regularly received hemodialysis for three months or more. Meanwhile, the exclusion criteria were patients with cognitive impairment, psychiatric patients, and in critical conditions.

\section{Instruments}

Research instruments in this study included demographic data and Chronic Kidney Disease Symptom Burden Index (CKD - SBI). The questionnaires were administered by the researcher during dialysis time. Demographic form consisted of 9 variables involving age, gender, education, marital status, duration of hemodialysis (month), employment status, comorbidities, and body mass index (BMI) utilized. Age and duration of hemodialysis was measured as continuous data. In the description of patient characteristics, gender, education, marital status, employment status, and BMI were measured as categorical data. Gender was divided into male and female. Education level was divided into elementary school, junior high school, senior high school, and university. Marital status was categorized into married, single, and widow. Employment status was divided into work, no work, and retired. BMI was categorized based on WHO regulation involving underweight (below 18.5), normal $(18.5-24.9)$, overweight $(25-29.9)$, and obesity (above 30) (WHO, 2020). For comorbidities, all comorbid disease would be measured by using the Charlson comorbidity index $(\mathrm{CCI})$.

CKD Symptom Burden Index (CKD-SBI) questionnaire was used to identify symptom burden in patients on hemodialysis during the previous 4 weeks. CKD-SBI consisted of 32 questions which measured four dimensions of symptoms (occurrence, frequency, severity and distress). Firstly, patients were asked about occurrence of symptoms with yes or no question. If the patients answered yes, then the patients should continue to answer frequency, severity, and distress dimensions. If the patients answered no, they did not need to continue to other dimensions (Almutary, Bonner, \& Douglas, 2015).

Higher score indicated higher symptom occurrence. For occurrence, no answer was equal to 0 , and yes answer was equal to 1 . Thus, the possible range for occurrence was 0 to 32. Furthermore, the frequency, severity, and distress of symptoms were measured with numerical rank scoring from 0-10. Participants rate frequency dimension ranged from never to constant, severity dimension from none to very severe and distress dimension from none to very much. Possible range for severity, distress, and frequency was $0-320$, respectively. The total CKD$\mathrm{SBI}$ score was calculated by summing the scores of occurrences, distress, severity, and frequency dimensions of CKD-SBI, and the result was multiplied with the constant number $(0.1008)$. The total score ranged from $0-100$, and 100 indicated the highest symptom burden possible. Cronbach's alpha for CKD-SBI English version was 0.91 (Almutary et al., 2015). CKD-SBI was available in English and Arabic language only. Thus, the cross-cultural translation was conducted by adapting Guillemin 
and Beaton's guidelines. The validity was checked using item content validity index (I-CVI) and scale content validity index (S-CVI). The score for I-CVI was 0.92 , and S-CVI was 0.78. The Cronbach's alpha for Indonesian version was 0.95 .

\section{Ethical Consideration}

The ethical approval and permission of this study was obtained from Fatmawati Hospital and Cipto Mangunkusumo National Hospital. The number of ethical approval from the Institutional Review Board (IRB) was ND-1020/UN2.F1/ETIK/PPM.00.02/2019. The number of approval research permission from Fatmawati hospital was DM 01.01/VIII.2/9375/2019, and from Cipto Mangunkusumo National Hospital was LB/1.4.12/0118/2020. Ethical consideration was followed by the researcher and research assistants including informed consent, autonomy, anonymity, beneficence, and justice (Polit \& Beck, 2012). Firstly, the researcher gave the information clearly to the subjects about the title, purpose of study, procedures, the mechanism of protecting subject personal data and rights. After informed consent, the subjects could decide whether they would join in this study or withdraw anytime. If the subjects decided to participate, subjects then filled the questionnaire. After the subjects filled the questionnaire, the researcher checked for the completeness. Only complete questionnaires were used in data analysis. The researcher protected the data from any interest or harm by using coding system in data analysis to protect the subject privacy. Subjects received the same treatment from the researcher through the study although they might have a different belief, culture or religion among each other.

\section{Data Collection Procedures}

The researcher recruited one research assistant to collect the data. Research assistant was a female nurse who graduated from university and had work experience in hemodialysis unit for more than 2 years. In the current study, the research assistant had working experience as a research assistant and had done data collection. The research assistant

Tabel 1 Demographic Data

\begin{tabular}{lcc}
\hline \multicolumn{1}{c}{ Variable } & $\mathbf{n}(\%)$ & Mean and SD \\
\hline Gender & $145(45.3)$ \\
Female & $175(54.7)$ \\
Male & \\
BMI & $24(7.5)$ \\
Underweight (below 18.5) & $214(66.9)$ \\
Normal (18.5 - 24.9) & $67(20.9)$ \\
Overweight ((25 - 29.9) & $15(4.7)$ \\
Obese (30 and above) &
\end{tabular}

\begin{tabular}{lc} 
Marital Status & $28(8.7)$ \\
Single & $262(81.9)$ \\
Married & $30(9.3)$ \\
Widow & \\
Education & $30(9.3)$ \\
Elementary school & $28(8.7)$ \\
Junior high school & $171(53.4)$ \\
Senior high school & $91(28.4)$ \\
University & $192(60.0)$ \\
Work Status & $79(24.7)$ \\
Not Work & $49(15.3)$ \\
Work & $107(33.4)$ \\
Retired & $142(44.3)$ \\
Comorbidities $(\mathrm{CCl})$ & $71(22.1)$ \\
0 & \\
\hline 1-2 & \\
Above 3 & \\
\hline Age & \\
\hline Duration & \\
\hline
\end{tabular}


Table 2. Symptom Burden Description ( $N=320)$

\begin{tabular}{|c|c|c|c|c|}
\hline Symptom & $\begin{array}{c}\text { Symptom } \\
\text { Occurrence } \\
\text { n (\%) }\end{array}$ & $\begin{array}{c}\text { Symptom } \\
\text { Severity } \\
\text { (mean } \pm \text { SD) }\end{array}$ & $\begin{array}{c}\text { Symptom } \\
\text { Distress } \\
\text { (mean } \pm \text { SD) }\end{array}$ & $\begin{array}{c}\text { Symptom } \\
\text { Frequency } \\
\text { (mean } \pm \text { SD) }\end{array}$ \\
\hline Constipation & $152(47.5)$ & $1.67 \pm 2.24$ & $1.84 \pm 2.48$ & $1.83 \pm 2.61$ \\
\hline Nausea & $195(60.9)$ & $2.27 \pm 2.56$ & $2.46 \pm 2.73$ & $2.22 \pm 2.54$ \\
\hline Vomiting & $127(39.6)$ & $1.30 \pm 2.13$ & $1.42 \pm 2.25$ & $1.16 \pm 2.11$ \\
\hline Diarrhoea & $84(26.2)$ & $0.81 \pm 1.70$ & $0.82 \pm 1.68$ & $0.65 \pm 1.29$ \\
\hline Decreased appetite & $165(51.5)$ & $2.11 \pm 2.63$ & $2.22 \pm 2.70$ & $2.17 \pm 2.76$ \\
\hline Muscle cramps & $200(62.5)$ & $2.52 \pm 2.57$ & $2.69 \pm 2.71$ & $2.20 \pm 2.29$ \\
\hline Swelling in legs & $145(45.3)$ & $1.53 \pm 2.12$ & $1.68 \pm 2.30$ & $1.54 \pm 2.16$ \\
\hline Shortness of breath & $176(55.0)$ & $2.42 \pm 2.76$ & $2.59 \pm 2.91$ & $2.01 \pm 2.91$ \\
\hline Dizziness & $222(69.3)$ & $2.74 \pm 2.49$ & $2.90 \pm 2.60$ & $2.82 \pm 2.96$ \\
\hline Restless legs & $128(40.0)$ & $1.26 \pm 1.86$ & $1.34 \pm 1.95$ & $1.24 \pm 1.89$ \\
\hline Numbness or tingling & $165(51.5)$ & $1.86 \pm 2.21$ & $1.98 \pm 2.36$ & $1.96 \pm 2.49$ \\
\hline Lack of energy & $269(84.0)$ & $4.28 \pm 3.08$ & $4.42 \pm 3.09$ & $4.41 \pm 3.27$ \\
\hline Cough & $179(55.9)$ & $1.91 \pm 2.19$ & $2.10 \pm 2.38$ & $1.87 \pm 2.25$ \\
\hline Dry mouth & $189(59.0)$ & $1.97 \pm 2.09$ & $2.09 \pm 2.23$ & $2.59 \pm 2.95$ \\
\hline Bone or joint pain & $220(68.7)$ & $3.12 \pm 2.77$ & $3.26 \pm 2.85$ & $3.19 \pm 3.08$ \\
\hline Chest pain & $140(43.7)$ & $1.54 \pm 2.12$ & $1.62 \pm 2.21$ & $1.46 \pm 2.06$ \\
\hline Headache & $189(59.0)$ & $2.39 \pm 2.52$ & $2.53 \pm 2.65$ & $2.19 \pm 2.41$ \\
\hline Muscle soreness & $232(72.5)$ & $2.92 \pm 2.51$ & $3.10 \pm 2.64$ & $3.03 \pm 2.71$ \\
\hline Difficulty concentrating & $134(41.8)$ & $1.48 \pm 2.19$ & $1.55 \pm 2.30$ & $1.52 \pm 2.30$ \\
\hline Dry skin & $250(78.1)$ & $2.95 \pm 2.40$ & $2.97 \pm 2.36$ & $4.09 \pm 3.39$ \\
\hline Itching & $190(59.3)$ & $2.43 \pm 2.62$ & $2.61 \pm 2.79$ & $2.52 \pm 2.86$ \\
\hline Worrying & $174(54.3)$ & $2.31 \pm 2.77$ & $2.33 \pm 2.79$ & $2.12 \pm 2.60$ \\
\hline Feeling nervous & $151(47.2)$ & $2.09 \pm 2.77$ & $2.15 \pm 2.84$ & $1.92 \pm 2.64$ \\
\hline Trouble falling asleep & $202(63.1)$ & $3.13 \pm 3.24$ & $3.17 \pm 3.25$ & $3.33 \pm 3.49$ \\
\hline Trouble staying asleep & $197(61.5)$ & $2.77 \pm 3.06$ & $2.81 \pm 3.07$ & $3.06 \pm 3.43$ \\
\hline Feeling irritable & $135(42.1)$ & $1.79 \pm 2.55$ & $1.85 \pm 2.62$ & $1.74 \pm 2.51$ \\
\hline Feeling sad & $132(41.2)$ & $1.89 \pm 2.66$ & $1.93 \pm 2.72$ & $1.76 \pm 2.51$ \\
\hline Feeling anxious & $139(43.4)$ & $1.99 \pm 2.71$ & $2.08 \pm 2.79$ & $1.81 \pm 2.52$ \\
\hline Depression & $39(12.2)$ & $0.48 \pm 1.48$ & $0.51 \pm 1.55$ & $0.40 \pm 1.21$ \\
\hline Decreased interest in sex & $210(65.6)$ & $3.39 \pm 3.38$ & $2.92 \pm 2.99$ & $3.70 \pm 3.65$ \\
\hline $\begin{array}{l}\text { Difficulty becoming sexually } \\
\text { aroused }\end{array}$ & $211(65.9)$ & $3.41 \pm 3.36$ & $2.94 \pm 2.97$ & $3.67 \pm 3.65$ \\
\hline Nocturia & $149(46.5)$ & $1.20 \pm 1.74$ & $1.25 \pm 1.82$ & $3.67 \pm 3.65$ \\
\hline \multirow[t]{2}{*}{ Overall subscale } & $171.5(53.6)$ & $69.94 \pm 79.59$ & $72.11 \pm 81.71$ & $71.93 \pm 83.68$ \\
\hline & Mean \pm SD & & & \\
\hline Total score CKD SBI & $23.69 \pm 12.27$ & & & \\
\hline
\end{tabular}

received the explanation about this study and went through three hours training on how to collect the data, how to approach the patients, and how to interpret the data. Then, the researcher collaborated with the research assistant to collect the data from each hospital. In August to January 2019, the data collection conducted from Fatmawati hospital and Cipto Mangunkusumo National hospital.

Before collecting the data, the researcher asked permission from the head nurse in the hemodialysis unit and made a list of patient's names with their hemodialysis schedule. Both researcher and research assistant approached the patients who met with the inclusion criteria. Then, researcher visited hemodialysis unit based on the patient's schedule. The questionnaires were given in Indonesian language and expanded to the patients during dialysis time. Estimated time to complete the questionnaire was approximately 20 minutes per patient. Informed consent was given to the subjects 
before they filled out the questionnaires.

\section{Data Analysis}

The data from this research were analyzed using the Statistical Package for the Social Science (SPSS) version 17.00. Descriptions of demographic data and symptom burden were analyzed using descriptive analysis (univariate analysis). All categorical data are presented using a frequency distribution with totals and percentages and all continuous data are presented using the mean and standard deviation. $\mathrm{BMI}$ and duration were identified as categorical data in description data.

\section{Results}

A total of 320 data from Fatmawati hospital and Cipto Mangunkusumo hospital were in accordance with the inclusion and exclusion criteria and were included in the data analysis. The results of data analysis were presented. Based on Table 1, the majority of the sample was male ( $n=175 ; 54.7 \%)$, while the female population was only $45.3 \%$ ( $n=$ $145)$. The result showed that most of the patients had a normal BMI $(\mathrm{n}=214 ; 66.9 \%)$, married $(\mathrm{n}=$ $262 ; 81.9 \%$ ), graduated from senior high school $(n=$ $171 ; 53.4 \%$ ), did not work both full time or part time ( $\mathrm{n}=192 ; 60.0 \%)$, and had $1-2$ comorbidities $(\mathrm{n}=$ $141 ; 44.3 \%$ ) These were measured using Charlson's Comorbidity Index $(\mathrm{CCl})$. Table 2 also presented the age and duration of hemodialysis. The participants in this study were between 18 to 93 years old, the average for age was $51.50(\mathrm{SD}=14.56)$, and the mean for hemodialysis duration was 46.28 (SD = 43.76 ) or equal to 3.8 years.

\section{The Description of Multidimensional Symptom Burden}

Thirty-two symptom burdens (physical and psychological) in four dimensions (occurrence, severity, distress and frequency) were collected. A summary of symptom burden experienced by the population is presented in Table 2. For the total score result, the minimum score is 0.30 and the maximum score is 63.81. The mean and SD of the total score are $23.69 \pm 12.27$.

\section{a. Occurrence Dimension}

For occurrence dimension, there are 5 most prevalent symptoms burden such as lack of energy $(n=269 ; 84.0 \%)$, dry skin $(n=250 ; 78.1 \%)$, muscle soreness $(n=232 ; 72.5 \%)$, light headedness or dizziness ( $n=222 ; 69.3 \%$ ), and bone or joint pain $(n=220 ; 68.7 \%)$. Furthermore, more than $50 \%$ of the population also experienced decreased interest in sex $(n=210 ; 65.6 \%)$, difficulty in being sexually aroused $(n=211 ; 65.4 \%)$, trouble in falling asleep $(n=202 ; 63.1 \%)$, trouble in staying asleep $(n=197$; $61.5 \%)$, muscle cramps ( $n=200 ; 62.5 \%)$, itching $(n=$ $190,59.3 \%)$, headache $(n=189,59.0 \%)$, dry mouth $(n=189,59.0)$, cough $(n=179,55.9)$, shortness of breath ( $n=176,55.0 \%$ ), and numbness or tingling $(n=165,51.5 \%)$.

\section{b. Severity Dimension}

The severity of 32 the symptom burden reported by all participants had mean and SD of $69.94 \pm$ 79.59. The five most severe symptom burdens were lack of energy $(4.28 \pm 3.08)$, followed by difficulty of being sexually aroused $(3.41 \pm 3.36)$, decreased interest in sex $(3.39 \pm 3.38)$, trouble falling asleep $(3.13 \pm 3.24)$ and bone or joint pain (3.12 \pm 2.77$)$.

\section{c.Distress Dimension}

Furthermore, for the distress dimension, the majority of participants reported moderate to high symptom distress. The mean and SD for overall symptom distress were $72.11 \pm 81.71$. Five symptoms were found to be the most bothersome for all participants including energy deprivation (4.42 \pm 3.09 ), bone or joint pain (3.26 \pm 2.85 ), muscle soreness $(3.10 \pm 2.64)$, trouble in falling asleep $(3.17 \pm 3.25)$, and decreased interest in sex (2.92 $\pm 2.99)$.

\section{d.Frequency Dimension}

The fourth dimension is the frequency dimension. The mean for all participants in the frequency dimension was $71.93 \pm 83.68$. The five most frequent symptoms among all participants involved lack of energy $(4.41 \pm 3.27)$, dry skin $(4.09 \pm 3.39)$, decreased interest in sex $(3.70 \pm 3.65)$, difficulty of being sexually aroused $(3.67 \pm 3.65)$, and trouble falling asleep (3.33 \pm 3.49$)$.

\section{Discussion}

\section{Characteristics of Sample}

In the current study, the average age of the patients was 51.50 years old. This data was related to the previous study from Indonesia conducted by Kamil (2017) which mentioned that an average age of hemodialysis population in Indonesia was 53 years old. Three other studies mentioned an average age of patients with hemodialysis are between 50-60 years old (Almutary et al., 2013; Amro et al., 2016; Shim \& Cho, 2018; Yu, Huang, \& Tsai, 2012).

The current study also reported that the majority of the sample was male ( $n=175 ; 55 \%$ ). According to the Indonesian Renal Registry (IRR) in 2018, it was reported that $57 \%$ of new hemodialysis patients in Indonesia are male (IRR, 2018). Three other studies from different country including Saudi Arabia, Norway and Taiwan confirmed this report (Almutary et al., 2016; Amro et al., 2016; Shim \& Cho, 2018; Yu, Huang, \& Tsai, 2012).

A total of $81.9 \%$ of hemodialysis patients in the current study were married. This data was related to three previous studies (Almutary et al., 2016; Shim \& Cho, 2018; Yu, Huang, \& Tsai, 2012). The original study from Saudi Arabia reported that $59.6 \%$ 
of patients were married (Almutary et al., 2016). Furthermore, Shim and Cho (2018) from Korea reported that $56.3 \%$ of subjects were married.

The hemodialysis duration is approximately between 1-5 years. This data was also related with the previous study from Shim and Cho (2018) which reported that $70 \%$ of populations had undergone hemodialysis for less than 5 years. Only 30\% of populations underwent hemodialysis duration $>5$ years.

The current study reported that the majority of patients suffered 1-2 comorbid diseases including hypertension and diabetes. Hypertension occurred in $51 \%$ of populations, while diabetes occurred in 215 of populations. This result is similar to the IRR (2018) which reported the highest comorbidities among hemodialysis patients in Indonesia are hypertension and diabetes. Similar to the current study, the original study reported that $51.4 \%$ patients lived with 1-2 comorbidities (Almutary et al., 2016).

For the level of education, most hemodialysis patients in Indonesia have high school education. The original study had a lower level of educational, because $53.9 \%$ of them had had less than high school education status (Almutary et al., 2016). In South Korea, the education level of hemodialysis patients is higher. The majority of patients had been in school for more than 16 years.

The last characteristic data is the employment status, most of patients in the current study were unemployed due to their illness. Two studies reported similar issues (Lee \& Jeon, 2015; Shim \& Cho, 2018) where $63.4 \%$ of population in the study conducted by Shim and Cho (2018) were unemployed due to their illness. The original study reported that above $50 \%$ of their participants were employed.

\section{The Description of Multidimensional Symptom Burden}

The description of symptom burden among patients with hemodialysis in Indonesia is presented in four dimensions (occurrence, severity, distress, frequency) with a total of 32 symptoms assessed including physical and psychological symptoms. Present study captured symptom burden using comprehensive measurement tools. A comprehensive assessment of symptoms is important to gain better knowledge of the symptom burden.

The score of symptoms in each dimension has contributed to the total symptoms burden. The total symptom burden was 63.81 , indicating that more than 15 symptoms (from 32 symptoms) were frequent, severe and distressing to patients with hemodialysis. In the original study, the total symptom burden was higher than current study, which was 83.36 (Almutary et al., 2016). his may be due to the diversity of the population in previous studies which consist of patients with CKD stage 4, CKD stage 5 (non-dialysis), peritoneal dialysis, and hemodialysis. Meanwhile in this study, all participants received hemodialysis as a treatment.

The current study listed the 5 highest symptom burdens in each dimension. Occurrence dimension was dominated by physical symptoms such as lack of energy, dry skin, muscle soreness, dizziness, and bone or joint pain. Severity dimension was dominated by lack of energy, difficulty in becoming sexually aroused, decreased interest in sex, trouble in falling asleep, and bone or joint pain. Distressing symptoms were lack of energy, bone or joint pain, muscle soreness, trouble in falling asleep, and decreased interest in sex. The last was frequency dimension consisting of lack of energy, dry skin, decreased interest in sex, difficulty in becoming sexually aroused, and trouble in falling asleep.

Interestingly, lack of energy was consistently found as the highest symptom burden in all dimensions. This finding was related to the previous research which stated that fatigue or lack of energy was dominant and consistent among patients with hemodialysis along all dimensions (Almutary et al., 2016). The majority of patients on hemodialysis commonly experienced fatigue or lack of energy (Kustimah, Siswadi, Djunaidi, \& Iskandarsyah, 2020). Among patients on hemodialysis, fatigue may be caused by many factors such as inadequate hemodialysis treatment, demographic characteristics (older age and female), psychosocial problem (depression, anxiety, low social support), physiological factors (anemia, lower albumin serum, lower creatinine interdialytic weight gain), and low sleep quality (Horigan, 2012).

\section{Conclusion}

The authors found that the majority of hemodialysis patients in Indonesia were male, adult, with an average duration of hemodialysis 3.8 years, married, had normal weight, graduated from high school, did not work, and lived with 1-2 comorbidities. Patients with hemodialysis experience a burden of symptoms that have an impact on daily life. In this study, energy deprivation was the highest symptom burden among patients on hemodialysis.

\section{Recommendation}

Health care professionals need to identify symptom burden among hemodialysis patients comprehensively, which consist of two domains (physical and psychological) and four dimensions (prevalence, severity, frequency, and distress). Creating appropriate interventions for energy deficiency is also important to improve health-related quality of life among hemodialysis populations. 


\section{Disclosures and Acknowledgement}

The authors gratefully acknowledged the Fatmawati Hospital and Cipto Mangunkusumo Hospital for their support; and 320 hemodialysis patients for sharing their symptoms experience.

\section{Conflict of interest}

The authors declared that there was no conflict of interest.

\section{Funding Statement}

This research did not receive any specific grant from funding agencies in the public, commercial, or notfor-profit sectors.

\section{References}

Almutary, Douglas, \& Bonner. (2016). Multidimensional symptom clusters: An exploratory factor analysis in advanced chronic kidney disease. J Adv Nurs, 72(10), 2389-2400. https://doi.org/10.1111/jan.12997

Almutary, H., Bonner, A., \& Douglas, C. (2013). Symptom burden in chronic kidney disease: A review of recent literature. J Ren Care, 39(3), 140-150. https://doi.org/10.1111/j.17556686.2013.12022.x

Almutary, H., Bonner, A., \& Douglas, C. (2015). Arabic translation, adaptation and modification of the Dialysis Symptom Index for chronic kidney disease stages four and five. BMC Nephrol, 16, 36. https://doi.org/10.1186/ s12882-015-0036-2

Almutary, H., Bonner, A., \& Douglas, C. (2016). Which patients with chronic kidney disease have the greatest symptom burden? A comparative study of advanced ckd stage and dialysis modality. J Ren Care, 42(2), 73-82. https://doi.org/10.1111/jorc.12152

Amro, A., Waldum-Grevbo, B., von der Lippe, N., Brekke, F. B., Miaskowski, C., \& Os, I. (2016). Symptom clusters from dialysis to renal transplantation: A five-year longitudinal study. J Pain Symptom Manage, 51(3), 512-519.http://dx.doi.org/10.1016/j. jpainsymman.2015.10.012

Comrey, \& Lee. (1992). A first course in factor analysis. Lawrence Erlbaum Associates, Inc

Gapstur, R. L. (2007). Symptom burden: A concept analysis and implications for oncology nurses. Oncol Nurs Forum, 34(3), 673-680. https://doi. org/10.1188/07.ONF.673-680

Horigan, A. E. (2012). Fatigue in hemodialysis patients: A review of current knowledge. Journal of Pain and Symptom Management, 44(5), 715-724. https://doi.org/10.1016/j. jpainsymman.2011.10.015

International Society of Nephrology. (2018). About the International Society of Nephrology (ISN).
Retrieved October 18, 2020, from https:// ncdalliance.org/the-international-society-ofnephrology-isn

Kamil. (2017). Exploring factors related sleep quality among patients undergoing hemodialysis in Indonesia [Unpublished masters's thesis, National Cheng Kung University]. National Cheng Kung University. U00260807201700095300

Kustimah, K., Siswadi, A. G. P., Djunaidi, A., \& Iskandarsyah, A. (2020). Quality of life among patients undergoing haemodialysis in Bandung: A mixed methods study. Jurnal Keperawatan Padjadjaran, 8(1). https://doi. org/10.24198/jkp.v8i1.1330

Lee, S. J., \& Jeon, J. (2015). Relationship between symptom clusters and quality of life in patients at stages 2 to 4 chronic kidney disease in Korea. Applied Nursing Research, 28(4), e13-e19. https://doi.org/10.1016/j.apnr.2015.03.004

Lenz, E. R., Pugh, L. C., Milligan, R. A., Gift, A., \& Suppe, F. (1997). The middle-range theory of unpleasant symptoms: an update. ANS Adv Nurs Sci, 19(3), 14-27. https://doi. org/10.1097/00012272-199703000-00003

Murtagh, F. E., Sheerin, N. S., Addington-Hall, J., \& Higginson, I. J. (2011). Trajectories of illness in stage 5 chronic kidney disease: A longitudinal study of patient symptoms and concerns in the last year of life. Clin J Am Soc Nephrol, 6(7), 1580-1590. https://doi.org/10.2215/ CJN.09021010

Polit, D., \& Beck, C. (2012). Nursing research: Generating and assessing evidence for nursing practice (pp. 150-160). Philadelphia: Lippincott Williams \& Wilkins. * Remmers, H., Holtgräve, M., \& Pinkert. C.(2010). Stress and nursing care needs of women with breast cancer during primary treatment: A qualitative study. European journal of oncology nursing, 14, 1116. https://doi.org/10.1016/j.ejon.2009.07.002

Shim, H. Y., \& Cho, M. K. (2018). Factors influencing the quality of life of haemodialysis patients according to symptom cluster. J Clin Nurs, 27(9-10), 2132-2141. https://doi.org/10.1111/ jocn.13904

Indonesian Renal Registry. (2018). 9th report of Indonesian renal registry. Perkumpulan Nefrologi Indonesia. Retrieved December 12, 2020, from https://www.indonesianrenalregistry. org/data/INDONESIAN\%20RENAL\%20 REGISTRY\%202016.pdf

Thong, M. S. Y., van Dijk, S., Noordzij, M., Boeschoten, E. W., Krediet, R. T., Dekker, F. W., ... Group, f. t. N. S. (2008). Symptom clusters in incident dialysis patients: associations with clinical variables and quality of life. Nephrology Dialysis Transplantation, 24(1), 225-230. https://doi.org/10.1093/ndt/gfn449

Vadakedath, S., \& Kandi, V. (2017). Dialysis: 
A review of the mechanisms underlying complications in the management of chronic renal failure. Cureus, 9(8), e1603-e1603. https://doi.org/10.7759/cureus.1603

World Health Organization [WHO]. (2020). Mean body mass index (BMI). Retrieved December
12, 2020, from https://www.who.int/gho/ncd/ risk_factors/bmi_text/en/

Yu, I. C., Huang, J. Y., \& Tsai, Y. F. (2012). Symptom cluster among hemodialysis patients in Taiwan. Appl Nurs Res, 25(3), 190-196. https://doi. org/10.1016/j.apnr.2010.11.002 